\title{
Crack Detectability in Vertical Axis Cooling Pumps During Operation
}

\author{
N. Bachschmid, P. Pennacchi, ${ }^{*}$ and E. Tanzi \\ Dipartimento di Meccanica, Politecnico di Milano, Via La Masa 34, I-20158 Milano, Italy \\ P. Verrier, F. Hasnaoui, and K. Aabadi \\ Dep. Analyses mécaniques et acoustiques, EDF, 1 avenue du Général de Gaulle, \\ F-92141 Clamart, France
}

The problem which is faced in this article is the analysis of the effects of a transverse propagating crack on the vibrational behavior of a vertical axis cooling pump. The crack is assumed to develop in a section between the impeller and a seal, preventing the hot water to flow upwards along the rotor shaft. The pressurized seal is fed with an injection of cold water, and crack initiation may be due to a thermal striping phenomenon. Afterwards, crack growth could be driven by a combination of thermal and mechanical loads, causing alternate cyclic stress in the shaft. Cracking instances of this type have been reported worldwide in several machines of similar design. In this article, the fact is emphasized that the crack behavior is likely to be influenced by the thermal field and by the water pressure in the cracked area. A dynamical lineshaft model, integrated by an original representation of the crack, has been developed to investigate the possible vibratory symptoms related to a crack propagation. The vibrations are generally measured in correspondence of a rigid coupling which connects the motor shaft to the pump shaft, in a position which is rather far away from the crack. $1 \times$ rev., $2 \times$ rev., and $3 \times$ rev. vibration components, which are generally displayed by the machine condition monitoring system and are the most significative symptoms of the presence of a transverse crack in a rotating shaft, are calculated.

Keywords Crack, Rotordynamics, Reactor coolant pump, Detection, Monitoring, Thermal gradients

Received 30 June 2003; in final form 10 September 2003.

*Corresponding author. Tel.: +39-02-2399-8440, Fax: +39-022399-8492. E-mail: paolo.pennacchi@polimi.it

\section{INTRODUCTION}

In almost all nuclear plants worldwide, the cooling of the reactor is performed by single stage, vertical axis centrifugal pumps. These pumps can be referred to either as main coolant pumps (which are often called reactor coolant pump (RCP) in service at pressurized water reactor (PWR) plants) or as recirculation pumps (in service at boiled water reactor (BWR) plants). The pumps are driven by electric motors and their running speed is close to $1800 \mathrm{rpm}$ in the U.S. (sometimes $1200 \mathrm{rpm}$ ) or $1500 \mathrm{rpm}$ in Europe.

The typical design of a reactor cooling pump includes the following features:

1. The motors are generally equipped with tilting pad radial and thrust bearings.

2. The pump has one radial bearing and several dynamic seal assemblies mounted along the shaft. The pump shaft is connected to the motor shaft by a rigid coupling.

One critical point of the design is the portion of shaft in correspondence to the sealing device in which the hot reactor water is prevented from flowing out by cold pressurized sealing water. High thermal stresses arise in this transition zone. Generally the shaft is protected by a metallic sleeve, but in many pumps, cracks of different sizes (supposedly caused by thermal fatigue) have been found during inspections after several years of operation, affecting the sleeve or the shaft (Kato et al., 1992). In some rare cases, a transverse crack has propagated to consistent depths within the shaft-most likely originating from surface microcracks - but the simultaneous increase in vibration levels shown by the monitoring system allowed the operators to stop the machine and to replace the rotor in order to avoid any failure during operation (Kato et al., 1992). The vibrations are generally measured by two proximity probes in correspondence to the coupling between electric motor and pump; the only measuring point is therefore rather far away from the impeller of the pump (on which the exciting forces act due to the operating fluid and to 
the mechanical unbalance) and from the section close to the seal in which the transverse crack is suspected to develop. Generally, the vibrations are recorded only at the operating speed since the starting and run down transients are too fast to allow the collection of significant data. The range of vibration levels in normal operating conditions (i.e., no particular fault is present on the machine, the excitation is due to the operating fluid, and to the residual mechanical unbalance only) is rather wide: from 20$150 \mu \mathrm{m}$. The dynamical behavior of machines of similar design can therefore be quite different; smaller differences in the design of the seal, the pump bearing, and the impeller-casing clearances have a strong influence on stiffness and damping of the system and on the hydraulic forces acting on the impeller. The range of dynamic behaviors observed in these machines is much wider than in horizontal axis turbogroups. This might be related to the fact that the load transmitted on the radial bearing in vertical machines is much smaller with respect to horizontal machines. In vertical pumps, the load is given by the stationary hydraulic force acting on the impeller which is expressly designed to stabilize that bearing. However, a still higher bearing action is furnished by the pressurized seal, which is close to the bearing. The result is that load, stiffness, and (especially) damping of bearing and seal may show a high sensitivity to small differences in design or in assembling tolerances so that the responses of assumedly similar machines can be quite different.

The behavior of a transverse crack in a vertical machine is also quite different from that generally observed on a horizontal machine. In this latter case, the breathing behavior (the opening and closing of the crack) is mainly determined by the constant load due the weight and the bearing alignment conditions (Dimarogonas, 1996; Mayes and Davies, 1976; Grabowski, 1979). In the vertical machine, the radial constant load is small and the breathing could be determined by the direction of the axial force. Thermal stresses may influence the behavior of the crack and also the high pressure fluid, entering between the crack faces and forcing its opening. As a result, the crack behavior is difficult to be modeled, and therefore it is difficult to calculate and predict its effect on the vibrations of pump.

The aim of this article is to set up a rotordynamics modeling approach to predict the typical vibration behavior of a RCP shaft that would exhibit hypothetical deep crack. Several simulations are carried out to find out the possible symptoms of this crack and analyze to which extent the calculated results are consistent with the experimental results reported in international literature. The final goal of this numerical study is then to discuss how and when a transverse shaft crack may generate vibrations of sufficient amplitude in the measuring station to allow an early detection by a monitoring supervisory system.

\section{DESCRIPTION OF THE PUMP}

Figure 1 represents the sketch of a typical RCP. The location of bearings, seal, and measuring station are shown. Referring to the pump operating parameters defined by the manufacturers, the following assumptions have been made regarding the pump global design:

i) Discharge pressure/temperature $15.5 \mathrm{MPa} / 290^{\circ} \mathrm{C}$

ii) Pressure of sealing water around $16 \mathrm{MPa} /$ temperature $35^{\circ} \mathrm{C}$

iii) Nominal speed $1500 \mathrm{rpm}$

Given the geometries of impeller and volute, the global mechanical load acting on the shaft can be defined as the sum of the elementary loads (Stepanoff, 1967) named hereafter:

i) Axial load (including weight of impeller)

ii) Radial fixed load related to unbalance

iii) Radial rotating load related to discharge nozzle

iv) Mechanical residual unbalance

v) Torsional load.

Measures of changes in amplitudes and phases of $1 \times$ rev., $2 \times$ rev., and $3 \times$ rev. components are widely used in condition monitoring systems for fault detection. The $2 \times$ rev. analysis is generally the most convenient way to detect a crack since other many phenomena can have an effect on the $1 \times$ rev. component. The present analysis deals with the possibility of having knowledge of a crack from the measuring station data, especially from the $2 \times$ rev. component of the dynamical response.

Figures $2 \mathrm{a}$ and $2 \mathrm{~b}$ show the typical vibration trend evolutions recorded by the proximity probes during a crack propagation sequence. These curves derive from the experimental results presented in the literature (EPRI, 1992), and show the influence that a transverse crack may have on the standard monitoring parameters implemented by the utilities. Figure 3 shows the finite beam element model used for the simulations. Stiffnesses of bearings and seals, at normal operating speed, are reported in Table 1, while the supporting structure is supposed as rigid.

The literature review pointed out some uncertainties in the determination of the hydraulic thrust load and radial loads and of the stiffness and damping coefficients of the pump bearing and seal. It is further reasonable to suppose an increase of the hydraulic radial forces when the impeller eccentricity increases (e.g., due to the crack) and a consistent change in stiffness and damping occur, mainly in the seal, due to big-sized orbits of the shaft in the seal (for which linearized coefficients are not valid anymore), when the vibrations increase.

\section{UNBALANCE RESPONSE}

In order to characterize the dynamical behavior of the shaft, a frequency response curve has been calculated applying a standard unbalance load to the impeller and simulating a speed transient. Additional mass unbalances are usually considered (on the flywheel, on the motor coils, or on the rigid coupling); however, for our purpose (influence of a crack located between the seal and the impeller), they have a negligible effect on the dynamical behavior of the crack. The resulting vibrations are shown in Figure 4 for the measuring station, in Figure 5 for the seal, and 


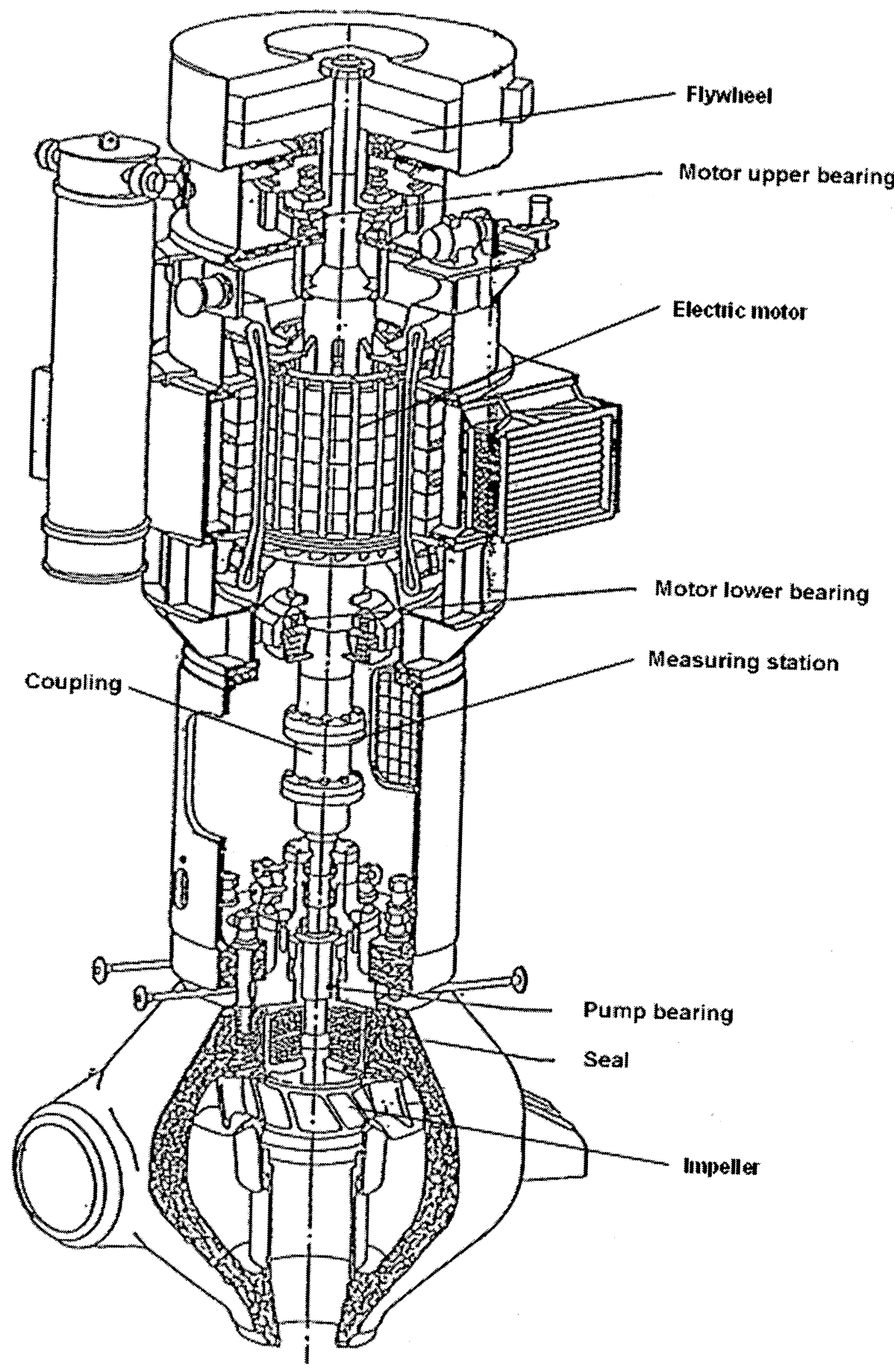

FIGURE 1

Typical layout of a reactor coolant pump (RCP).

in Figure 6 for the lower bearing. A first critical speed is found below $800 \mathrm{rpm}$ and another critical speed is located just above $1000 \mathrm{rpm}$.

Approaching the normal operating speed (1500 rpm), the vibrations tend to increase. By extending the speed range to up $3000 \mathrm{rpm}$ (not shown in the graphs), 2 other highly damped critical speeds can be recognized at around $1600 \mathrm{rpm}$ (just above the operating speed) and at 2400-2600 rpm. The vibrations at $1500 \mathrm{rpm}$ due to the unbalance have a distribution along the rotor shown in Figure 7a: the impeller has obviously the maximum values. The order of magnitude of the vibration amplitudes predicted by the model were in good agreement with the 

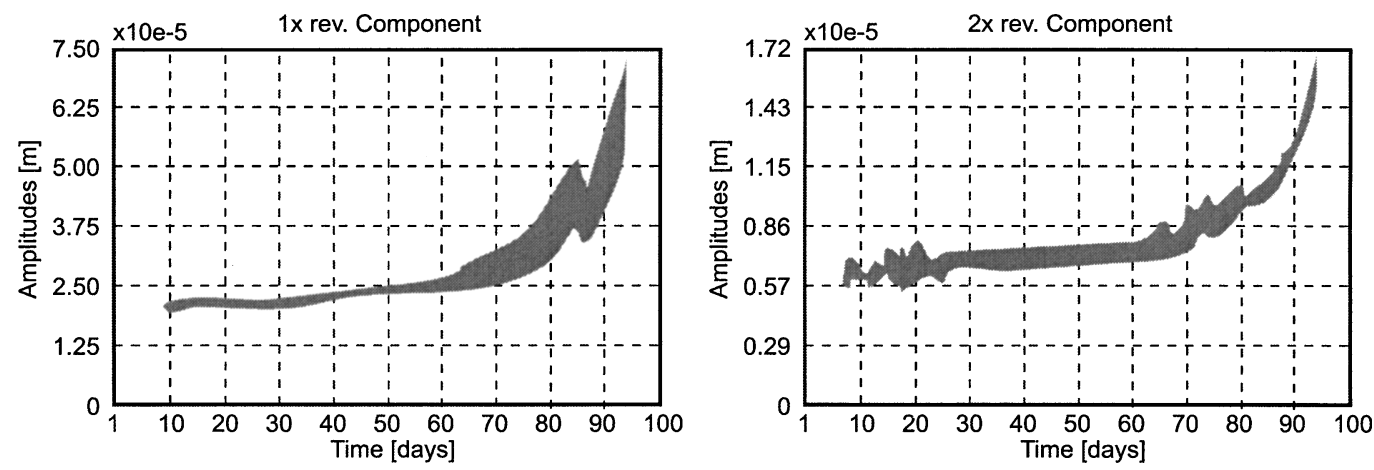

(a)
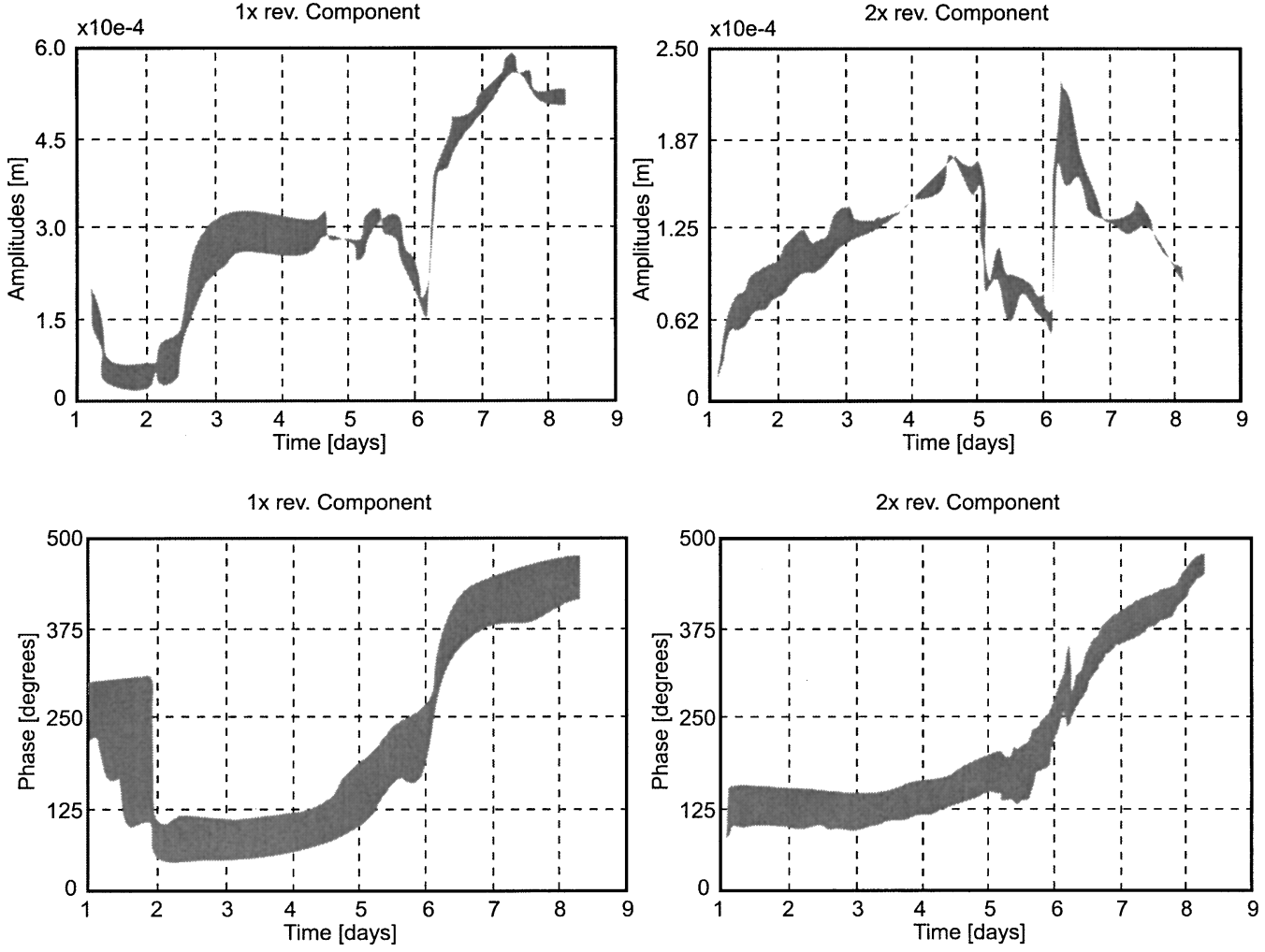

(b)

\section{FIGURE 2}

Typical vibration trend measured by the proximity probes in the measuring station of a RCP.

experimental values recorded by the measuring stations on similar machines.

A propagating crack generally produces a bow, which can be magnified by thermal stresses and by the water pressure penetrating between the two crack faces. The bow also generates $1 \times$ rev. vibrations Figure $7 \mathrm{~b}$ shows the deflection shape corresponding to two constant bending moments applied to the element in which we assume the presence of a transverse crack.

The impeller exhibits similar vibration amplitudes as those excited by the unbalance, but in the measuring station the values are usually found to be somehow smaller. Therefore, it seems that the assumed crack location close to the wheel is not a favorable configuration with view to early vibration detection, given the present location of vibration measurements in the utilities.

As is well known, a transverse crack consistently excites $2 \times$ rev. vibration components. Figure 7c shows the $2 \times$ rev. deflection shape obtained by means of a $2 \times$ rev. bending moment of same value. The maximum is in correspondence of the seal and rather small values are measured in the measuring station.

\section{THERMAL EFFECTS}

The vertical axis coolant pumps generally used in a nuclear power plant are subjected to high temperature gradients. This 


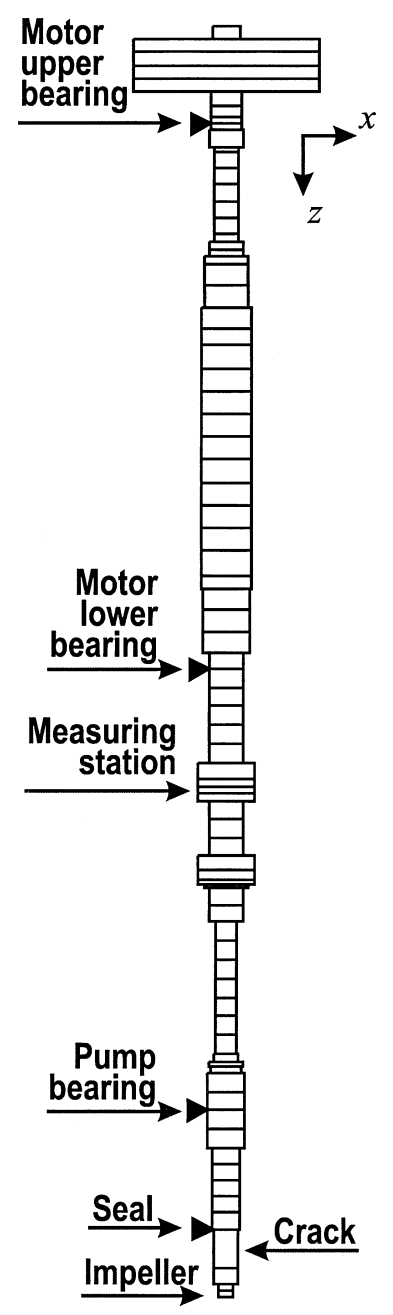

FIGURE 3

Finite beam element model of the RCP used for the simulations.

thermal gradient, due to the fact that the upper part of the shaft is surrounded by cool pressurized sealing water while its bottom is in contact with the fluid heated by the reactor, generates thermal stresses. The gradient is spread over a small zone where the shaft is protected by a metallic sleeve. In spite of this thermal protection brought by the sleeve, evidence was found that the shafts can still sometimes be subjected to cyclic thermal loads. This mechanism has caused the initiation of thermal fatigue microcracks in many machines (thermal striping phenomenon).

In this study, the thermal-hydraulic mixing of cold and hot water has been disregarded and the thermal gradient has been modeled considering a boundary close to the crack position, above which the temperature is $35^{\circ} \mathrm{C}$ and under which the temperature of the fluid is $290^{\circ} \mathrm{C}$. In a real situation, the thermal gradient could be smoother.

The aim of this analysis is to show how thermal loads can influence the behavior of the crack. To study this phenomenon, numerical calculations have been performed on 2D-axisymmetrical and 3D-models with the Code_Aster ${ }^{\complement}$ software, a finite element code dedicated to structural analyses developed by EDF (a free open source software: www.code-aster.org).

\section{D-Axial Symmetric Finite Element Modeling}

Only the shaft and the metallic sleeve protection are modeled (the crack is not represented) in order to show the effect of the thermal loads on the axial stress $\sigma_{z z}$. Figure 8, which represents an axial sectional view of one half of the shaft, shows how the shaft is mechanically affected by thermal loads. In the upper part (where the shaft is in contact with cold water) of the outer shaft surface a maximum of more than $50 \mathrm{MPa}$ of compressive stress is obtained below the sleeve and similar values of tensile stresses can be predicted in the inner part of the shaft. This is due to the fact that the inner part of the shaft is elongated more than the skin, as can be inferred from the temperature distribution shown in Figure 9.

In the lower part of the shaft, the opposite tension/compression distribution can be found along the radial direction. Therefore, if the boundary is located above the crack, tensile stresses develop in correspondence with the crack which could facilitate its opening; if the boundary is below, compressive stresses arise which force the closing of the crack.

This can better be seen with the 3D-model in which a theoretical transverse crack has been represented.

\section{D-Finite Element Modeling}

A rather small crack has been introduced in the 3D-model and the deformations due to the thermal loads have been calculated.

TABLE 1

Bearing/Seal Characteristics at $1500 \mathrm{rpm}$

\begin{tabular}{|c|c|c|c|c|c|c|c|c|}
\hline \multirow[b]{2}{*}{ Bearing } & \multicolumn{4}{|c|}{ Stiffness coefficients $[\mathrm{N} / \mathrm{m}]$} & \multicolumn{4}{|c|}{ Damping coefficients $[\mathrm{Ns} / \mathrm{m}]$} \\
\hline & $k_{x x}$ & $k_{x y}$ & $k_{y x}$ & $k_{y y}$ & $c_{x x}$ & $c_{x y}$ & $c_{y x}$ & $c_{y y}$ \\
\hline Motor upper bearing & $4.0 \mathrm{e} 8$ & $1.9 \mathrm{e} 5$ & $-1.9 \mathrm{e} 5$ & $3.8 \mathrm{e} 8$ & $1.8 \mathrm{e} 6$ & $-4.9 \mathrm{e} 2$ & $4.8 \mathrm{e} 2$ & $1.7 \mathrm{e} 6$ \\
\hline Motor lower bearing & $4.7 \mathrm{e} 8$ & $9.4 \mathrm{e} 4$ & $-2.0 \mathrm{e} 5$ & $1.2 \mathrm{e} 8$ & $1.3 \mathrm{e} 6$ & $-3.0 \mathrm{e} 2$ & $7.7 \mathrm{e} 2$ & $4.4 \mathrm{e} 5$ \\
\hline Pump bearing & 0 & $-3.2 \mathrm{e} 8$ & $3.1 \mathrm{e} 8$ & 0 & $4.0 \mathrm{e} 6$ & $-1.1 \mathrm{e} 5$ & $1.1 \mathrm{e} 5$ & $4.1 \mathrm{e} 6$ \\
\hline Seal & $1.3 \mathrm{e} 7$ & $-3.8 \mathrm{e} 6$ & $3.8 \mathrm{e} 6$ & $1.3 \mathrm{e} 7$ & $1.0 \mathrm{e} 5$ & $-7.9 \mathrm{e} 3$ & $-7.9 \mathrm{e} 3$ & $1.0 \mathrm{e} 5$ \\
\hline
\end{tabular}



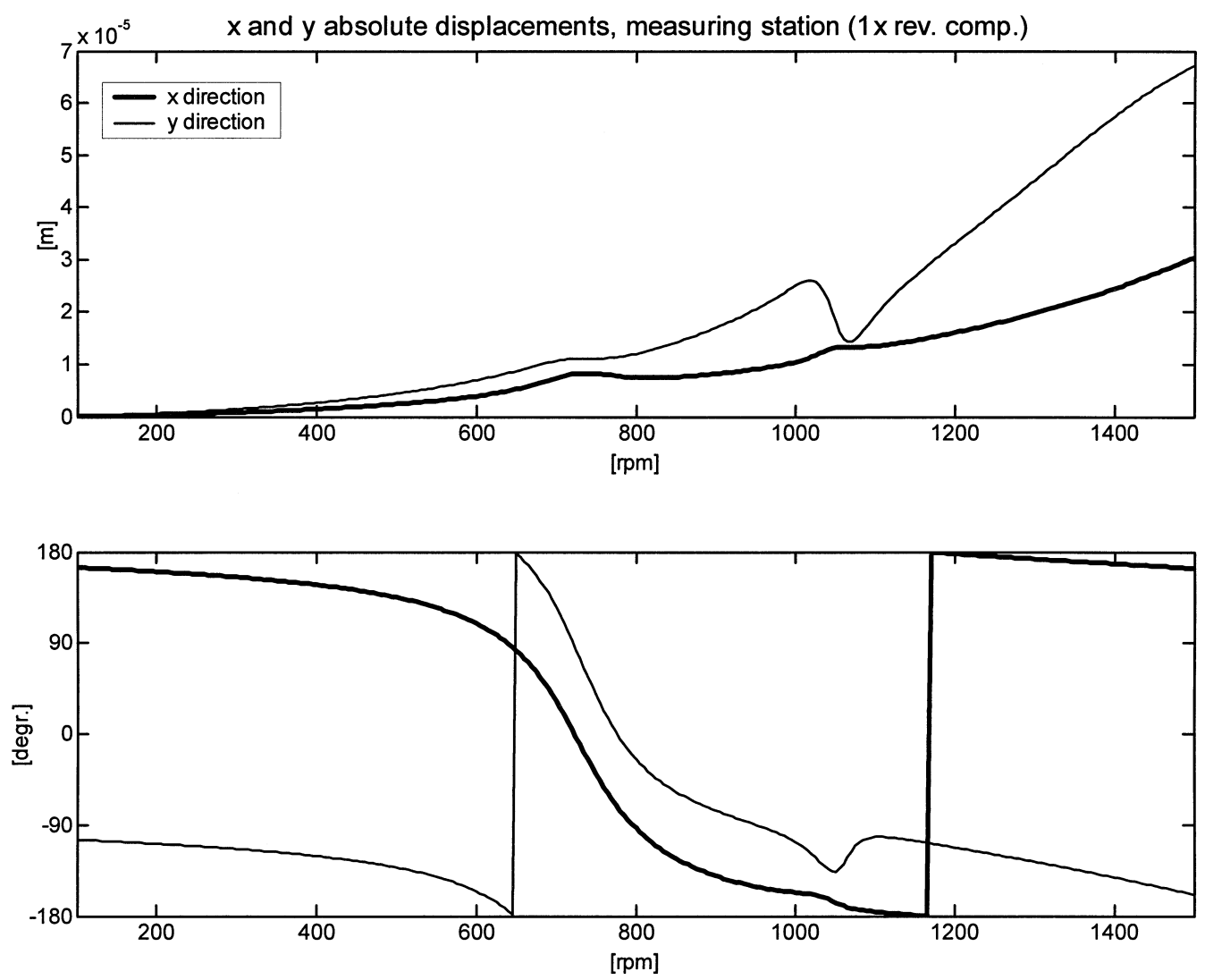

FIGURE 4

Unbalance simulated response in the measuring station.

The results are shown in Figure 10 in which the left side shows the situation with the thermal boundary position below the crack and the right side shows the results with the boundary above the crack. As represented in the figure, the crack is held closed in the first case, whereas it can be held open in the second case.

It is difficult to argue exactly where the boundary will be located in operating conditions. Some researchers suggested a situation in which the vertical location of the boundary could fluctuate, randomly or in a deterministic way, generating highcycle thermal fatigue. This configuration is opposed to a lowcycle thermal fatigue scenario, which in turn would be associated with the small number of start-ups of the pump.

It seems reasonable to assume the following about the thermal stresses:

- They are responsible for the microcrack generation.

- They contribute to the propagation of the crack.

Deterministic analysis of the crack growth mechanism depends on many factors, and may be influenced by the local stress distribution around the crack which turns out to be rather complex. The stress field in the shaft can be described as the sum of a constant stress distribution and of a variable alternating stress. On the one hand, the thermal load, the constant axial load, the mass unbalances, and the water pressure entering between two crack faces generate a constant stress distribution within the shaft. On the other hand, the bending moment is due to the constant radial hydraulic force (related to the discharge nozzle) and the unsteady components of torsion and axial force generating alternating stresses, which could also be amplified by some resonances in the system.

\section{CRACK RESPONSE CALCULATION METHOD}

The method which is described in detail in Bachschmid et al. (2002) is composed by a simplified 1D-linear crack model which allows us to calculate the angular position dependent and therefore periodical stiffness of an equivalent length cracked beam, which can be expanded in a Fourier series (of which only the first three terms are held). These harmonic components are introduced in a finite beam element model of the shaft line. The dynamic behavior is represented by a standard mass, damping, and stiffness matrix equation, in which the stiffness is not constant but contains some harmonic components in correspondence of the cracked element:

$$
[K(\Omega t)]=\left[K_{m}\right]+\left[\Delta K_{1}\right] e^{i \Omega t}+\left[\Delta K_{2}\right] e^{2 i \Omega t}+\left[\Delta K_{3}\right] e^{3 i \Omega t}
$$

Introducing this stiffness in the equations of motion of the rotor, Eq. (2) is obtained where $\underline{W}$ is the weight force vector, 

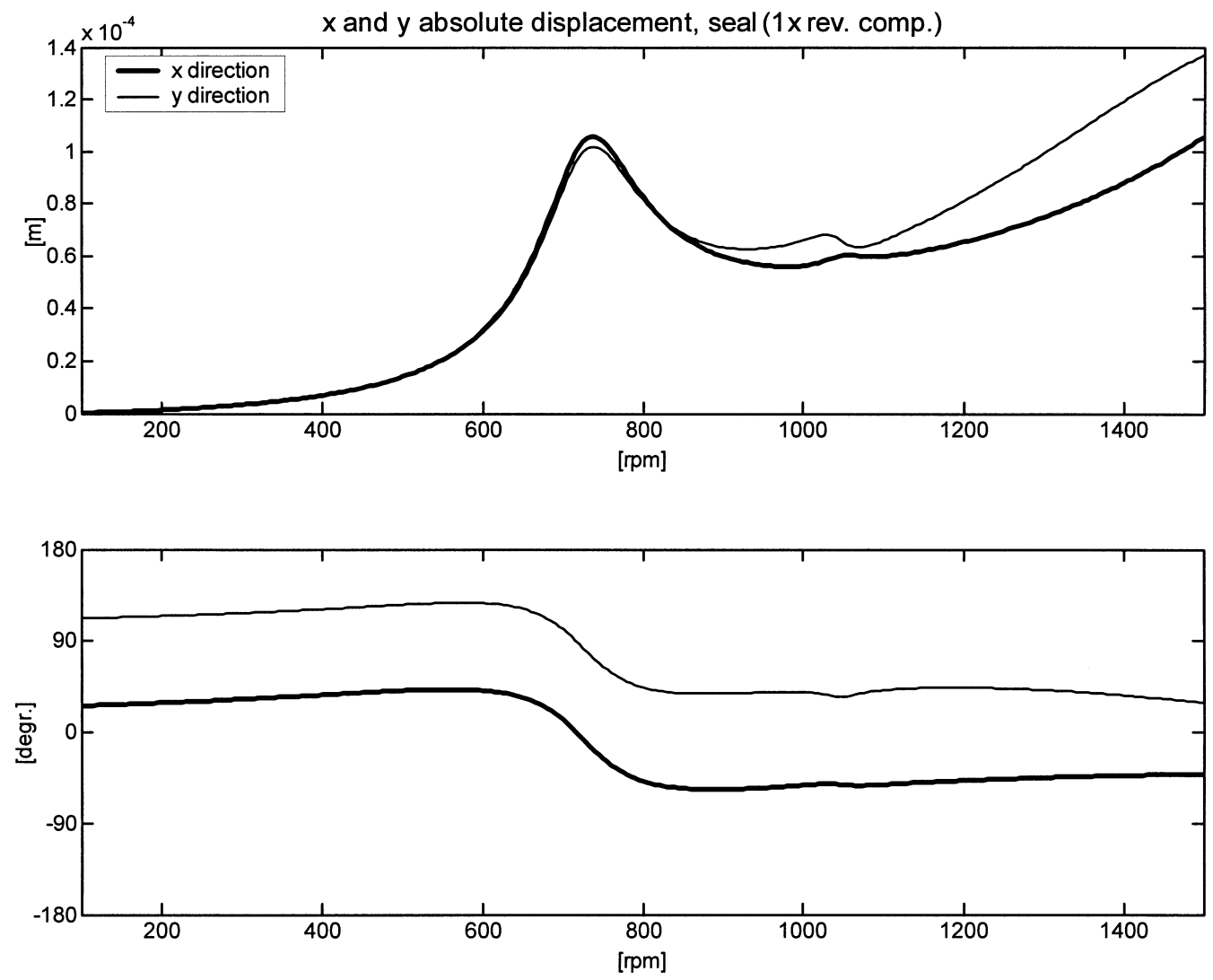

FIGURE 5

Unbalance simulated response in the seal.

and $\underline{F}_{n}$ is the $n$th harmonic component of the external forces ( $n=1$ for unbalances and bows, $n=2$ for axial unsymmetries, and so on).

$$
\begin{aligned}
{[M] \underline{\ddot{x}} } & +([R]+[G y r] \Omega) \underline{\dot{x}}+\left(\left[K_{m}\right]+\sum_{n}\left[\Delta K_{n} e^{n i \Omega t}\right]\right) \underline{x} \\
& =\sum_{n} \underline{F_{n}} e^{n i \Omega t}+\underline{W} \quad n=1,2,3
\end{aligned}
$$

Equation (2) has periodical coefficients and is solved by an iterative procedure; the harmonic balance approach in the frequency domain allows us to calculate the different harmonic components of the vibrations induced by the crack. The displacement $\underline{x}$ can be split in its statical and dynamical components according to Eq. (3) and finally Eq. (4) is obtained.

$$
\begin{aligned}
\underline{x}^{\prime} & =\underline{x}_{s}+\underline{x}_{d} \\
{[M] \underline{\ddot{x}}_{d} } & +([R]+[G y r] \Omega) \underline{\dot{x}}_{d}+\left[K_{m}\right] \underline{x}_{d} \\
& =\sum_{n} \underline{F}_{n} e^{n i \Omega t}-\sum_{n}\left[\Delta K_{n} e^{n i \Omega t}\right]\left(\underline{x}_{s}+\underline{x}_{d}\right)
\end{aligned}
$$

Since $\underline{x}_{d}$ is periodical, it can be split into three harmonic components, $\underline{x}_{1}, \underline{x}_{2}$, and $\underline{x}_{3}$ (generally only $1 \times$ rev., $2 \times$ rev., and $3 \times$ rev. components are calculated), and each component $\underline{x}_{n}$ can be expressed by Eq. (5) and similarly $\Delta K_{n}$ by Eq. (6).

$$
\begin{aligned}
\operatorname{Re}\left(\underline{x}_{n} e^{i n \Omega t}\right) & =\frac{1}{2} \underline{x}_{n} e^{i n \Omega t}+\frac{1}{2} \underline{x}_{n}^{*} e^{-i n \Omega t} \\
\operatorname{Re}\left(\Delta K_{n} e^{i n \Omega t}\right) & =\frac{1}{2} \Delta K_{n} e^{i n \Omega t}+\frac{1}{2} \Delta K_{n}^{*} e^{-i n \Omega t}
\end{aligned}
$$

The equivalent force component vectors are then obtained by substituting Eqs. (5) and (6) in the last term of Eq. (4) and Eqs. (7)-(11) are derived.

$$
\begin{aligned}
\underline{F}_{0}= & \frac{\Delta K_{1}}{4} \underline{x}_{1}^{*}+\frac{\Delta K_{1}^{*}}{4} \underline{x}_{1}+\frac{\Delta K_{2}}{4} \underline{x}_{2}^{*}+\frac{\Delta K_{2}^{*}}{4} \underline{x}_{2} \\
& +\frac{\Delta K_{3}}{4} \underline{x}_{3}^{*}+\frac{\Delta K_{3}^{*}}{4} \underline{x}_{3} \\
\underline{F}_{1} e^{i \Omega t}= & \left(\Delta K_{1} \underline{x}_{s}+\frac{\Delta K_{2}}{2} \underline{x}_{1}^{*}+\frac{\Delta K_{3}}{2} \underline{x}_{2}^{*}\right. \\
& \left.+\frac{\Delta K_{1}^{*}}{2} \underline{x}_{2}+\frac{\Delta K_{2}^{*}}{2} \underline{x}_{3}\right) e^{i \Omega t} \\
\underline{F}_{2} e^{2 i \Omega t}= & \left(\Delta K_{2} \underline{x}_{s}+\frac{\Delta K_{3}}{2} \underline{x}_{1}^{*}+\frac{\Delta K_{1}}{2} \underline{x}_{1}+\frac{\Delta K_{1}^{*}}{2} \underline{x}_{3}\right) e^{2 i \Omega t}
\end{aligned}
$$



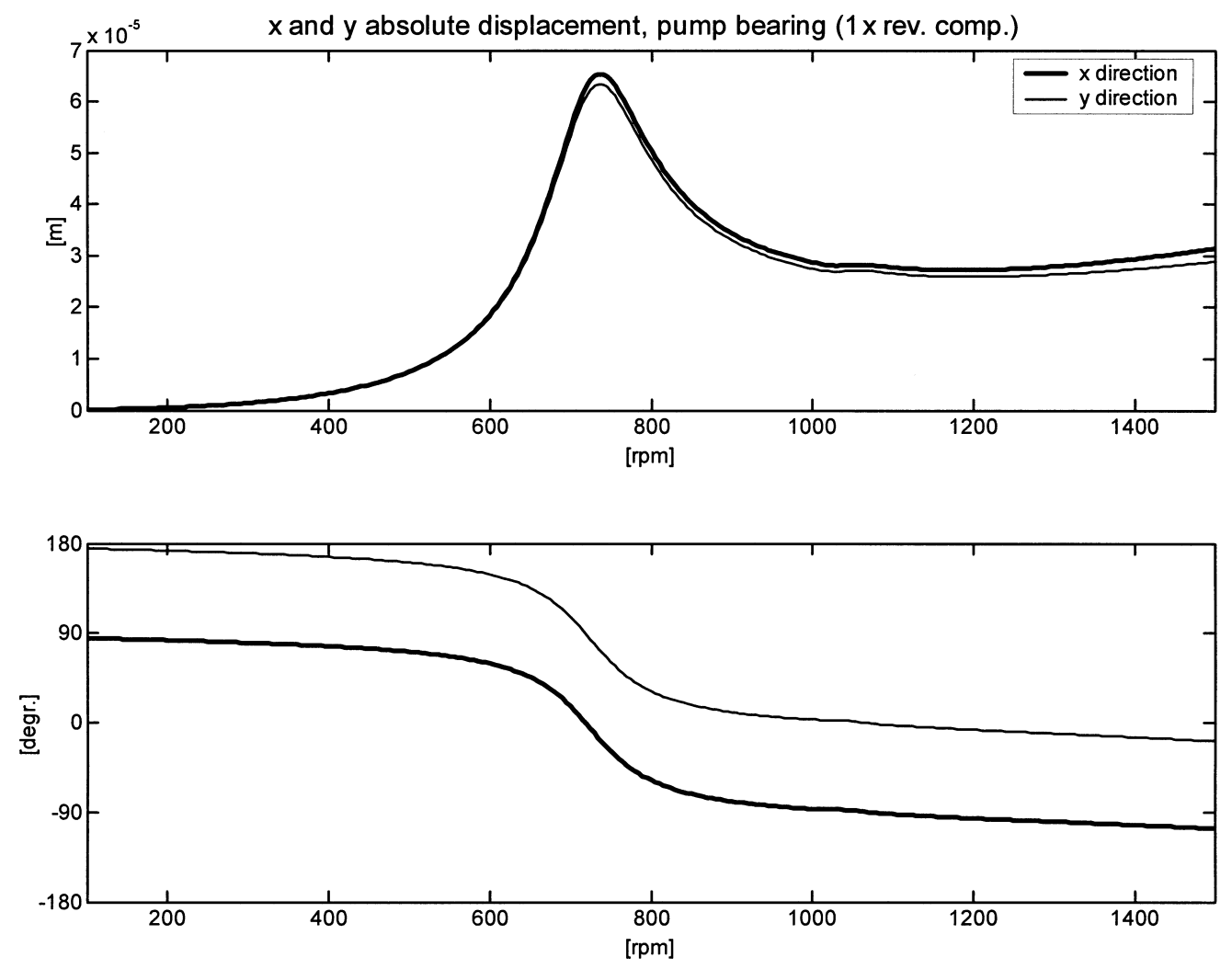

FIGURE 6

Unbalance simulated response in the pump bearing.

$$
\begin{gathered}
\underline{F}_{3} e^{3 i \Omega t}=\left(\Delta K_{3} \underline{x}_{s}+\frac{\Delta K_{1}}{2} \underline{x}_{2}+\frac{\Delta K_{2}}{2} \underline{x}_{1}\right) e^{3 i \Omega t} \\
\sum_{n}\left[\Delta K_{n} e^{n i \Omega t}\right]\left(\underline{x}_{s}+\underline{x}_{d}\right) \\
=\underline{F}_{0}+\underline{F}_{1} e^{i \Omega t}+\underline{F}_{2} e^{2 i \Omega t}+\underline{F}_{3} e^{3 i \Omega t}
\end{gathered}
$$

The expressions in Eqs. (7)-(11) are the forces (and moments) that are applied to the extremity nodes of the equivalent beam element and cause its statical and dynamical behaviors.

The simplified 1D-linear crack model allows us to calculate the breathing behavior, e.g., the gradually opening and closing mechanism during one revolution of the shaft.

The model accounts for thermal stresses and external forces, which influence the breathing mechanism. In the points where the stresses are compressive, contact occurs between the two faces of the crack; where the stresses are instead tensile, no contact occurs. The stresses are calculated assuming linear behavior and disregarding the presence of the crack; therefore the procedure is roughly approximated since the actual stress distribution is not linear at all but it has been extensively proved that the obtained results are in excellent agreement with cumbersome non-linear 3D-calculations.

The closed parts of the cracked area and the uncracked area both contribute to the second moments of area which determine the stiffness of the equivalent beam.
If the model is applied to the RCP rotor, it immediately appears that some of the external forces will tend to prevent the breathing mechanism and to maintain the crack in a fully opened configuration. The influence of the axial force would be to keep the crack open and the water pressure on the crack faces would act in the same way. The final crack behavior also depends on the thermal stresses and on the exact location of the thermal boundary along the shaft axis. Using standard design assumptions, the maximum bending stress due to the constant hydraulic force has been estimated numerically in the assumedly cracked area, with the dynamical model of the pump lineshaft. The maximum bending stress calculated in the lower part of the shaft is found to be significantly lower than the stresses derived from the water pressure (water pressure $=15.5 \mathrm{MPa}$ at steady state). In these operating conditions, it can be demonstrated that the lips of the crack never get in contact and that, as a consequence, the shaft will keep a constant bow in correspondence of the crack.

A perpetually open crack generates only $2 \times$ rev. components which are proportional to the stationary bending moment due to the constant hydraulic force. The $1 \times$ rev. components are generated by the developing bow, as well as by the mechanical and hydraulic unbalances. The combination of rotating crack and $1 \times$ rev. excitation generates also $3 \times$ rev. components. Due to the above considerations, the response of the shaftline has been calculated assuming a perpetually open crack, a bow in the 

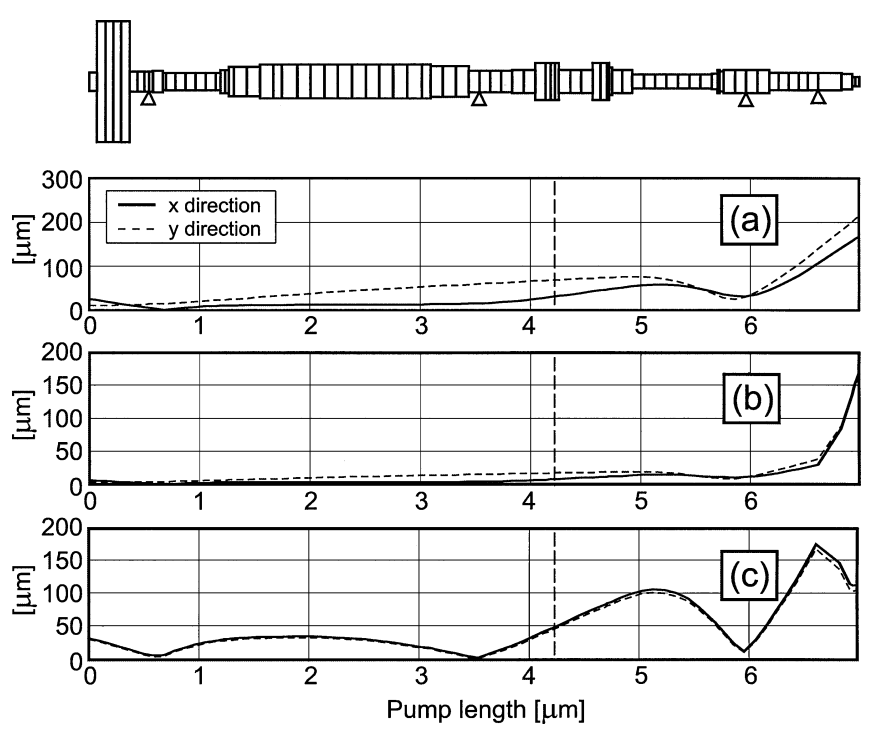

FIGURE 7

Vibrations at $1500 \mathrm{rpm}$ due to the unbalance (a) and to a bow which simulates a crack: $1 \times$ rev. (b) and $2 \times$ rev. (c). shaft due to the water pressure, disregarding the effect of thermal stresses and loading the impeller with hydraulic and mechanical unbalances.

\section{CRACKED ROTOR RESPONSE: RECTILINEAR CRACK WITH 50\% DEPTH}

Since the analysis is focused on the detectability of the crack in normal operating conditions (at its nominal speed of $1500 \mathrm{rpm}$ ) by analyzing the vibrations measured in correspondence with the coupling (available measuring point), the vibrations have been calculated at one rotating speed only, assuming different combinations of loads and different crack depths.

Table 2 shows the statical and dynamical harmonic components of the deflection of the shaft in the measuring station and in correspondence with the impeller. The considered loads are the following: bow due to water pressure, unbalance of $11000 \mathrm{~N}$ in phase or opposite to the bow, and constant radial force of $11000 \mathrm{~N}$.

When the unbalance is in phase with the bow, the $1 \times$ rev. component increases consistently, especially on the impeller.

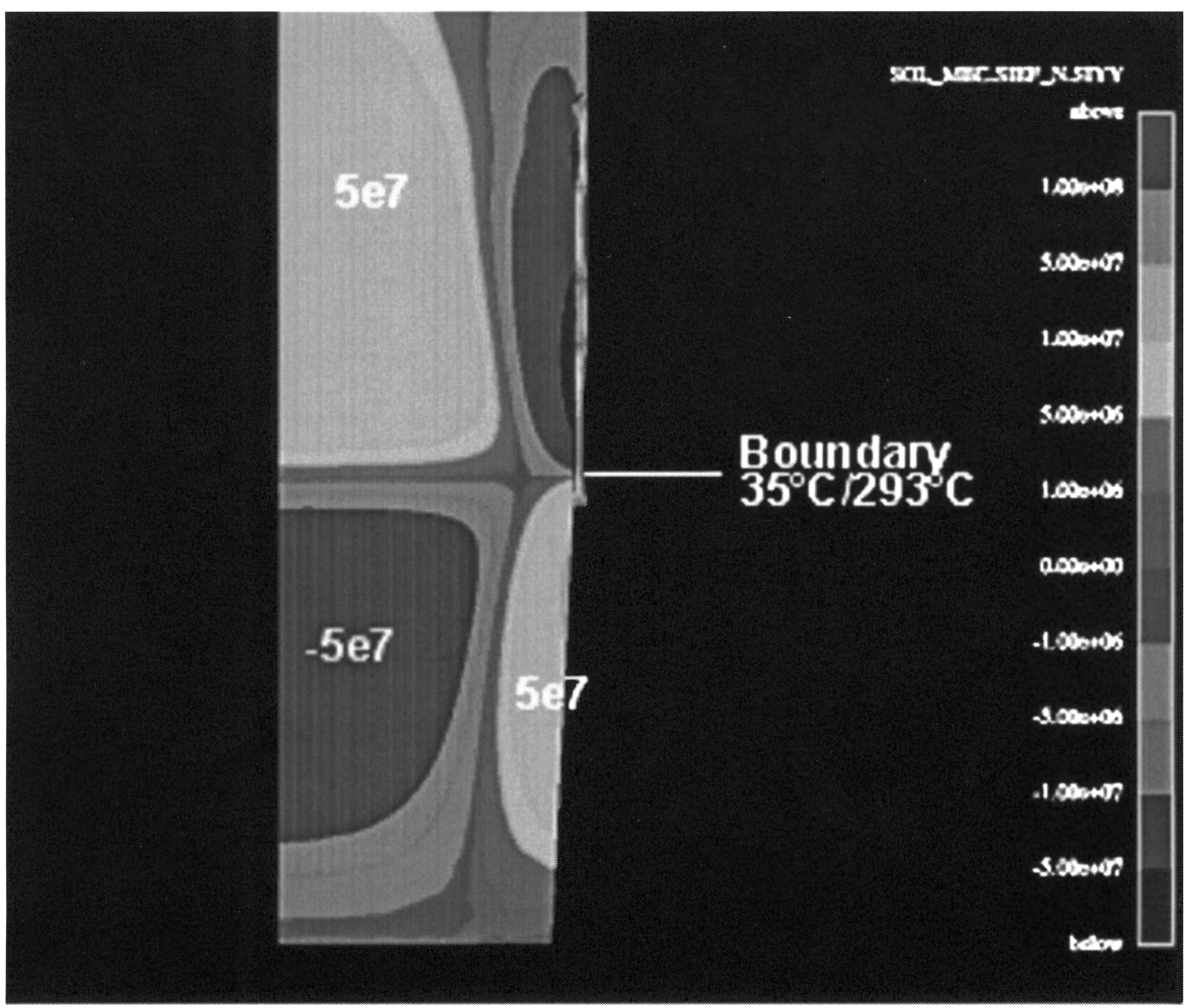

FIGURE 8

Axial thermal stresses $(\mathrm{Pa})$. 


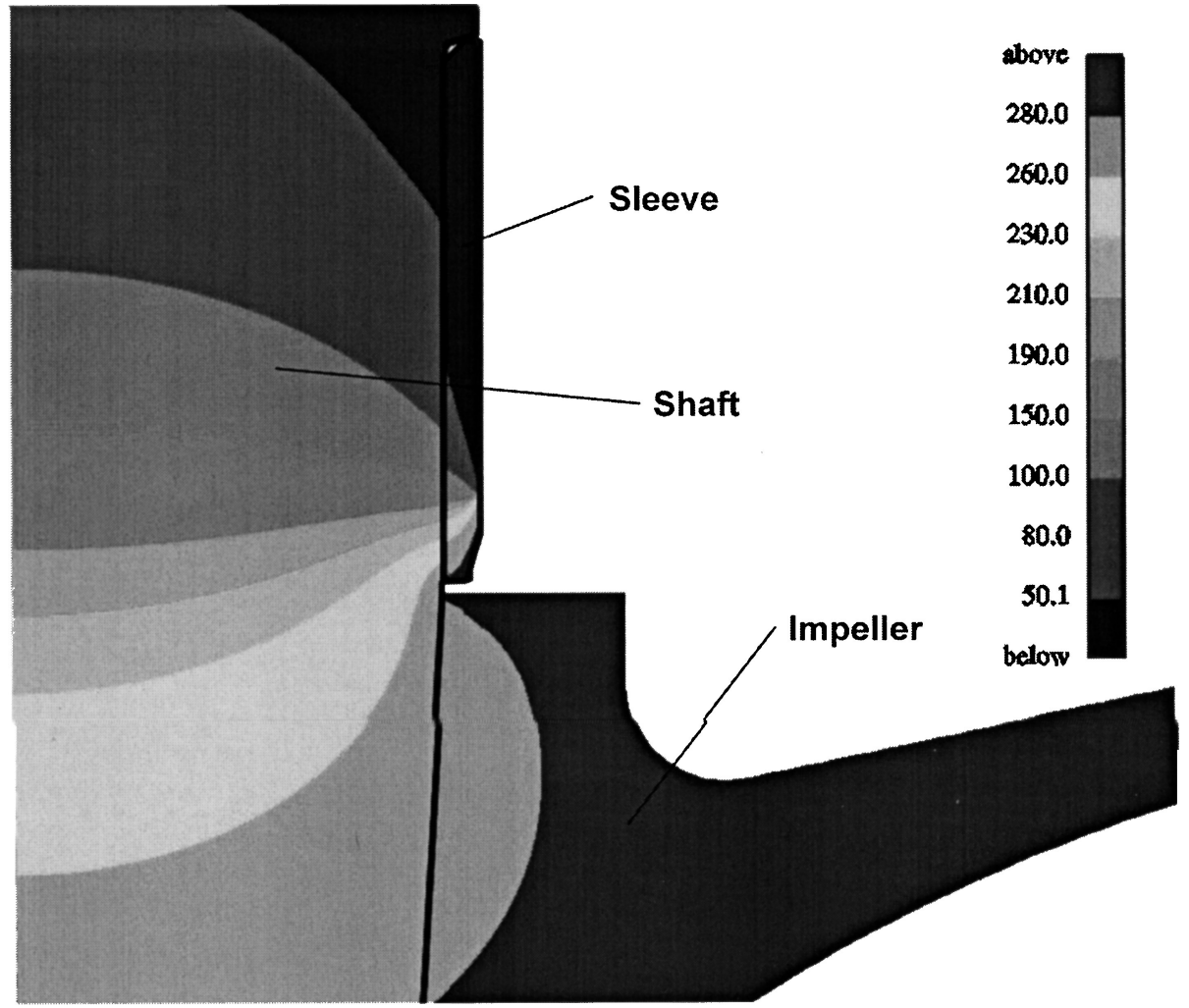

FIGURE 9

Temperature distribution.

This situation is probably the most likely to occur, since the crack starts from microcracks where the maximum axial tensile stresses are developed (that is diametrically opposite to the direction of the unbalance as can be deduced from dynamical deflection analysis, see Figure 12)
The statical $1 \times$ rev., $2 \times$ rev., and $3 \times$ rev. deflections shapes are represented in Figures 11-14. Although the pump radial bearing has a rather soft behavior, all deflection shapes $(1 \times$ rev., $2 \times$ rev., and $3 \times$ rev.) show a node or a quasi-node close to the bearing. All components have a measurable amplitude

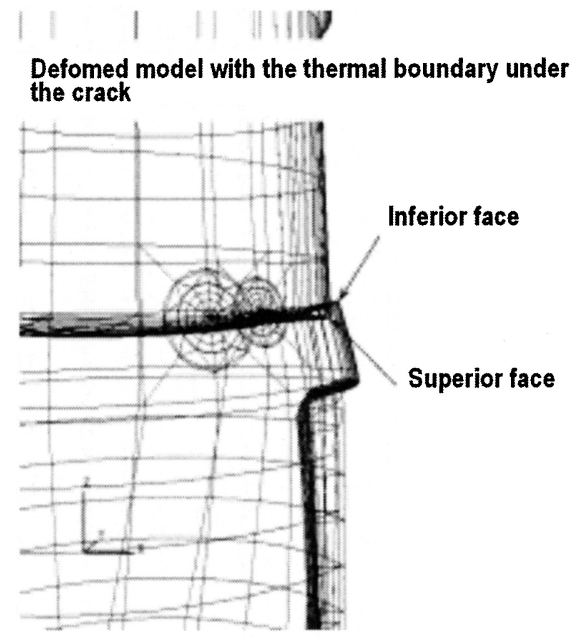

| | | | 17iks

Deformed model with the thermal boundary above the crack

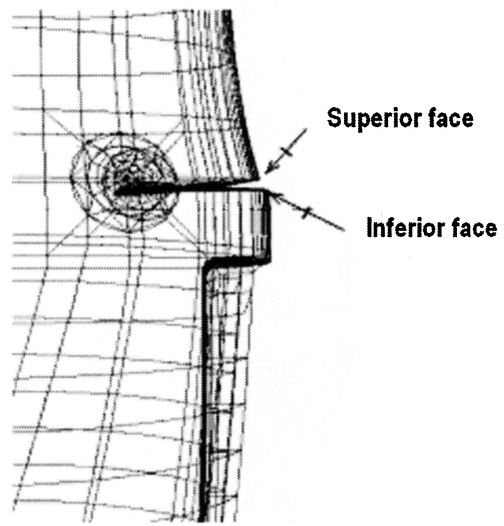

FIGURE 10

Crack behavior 3D-model. 
TABLE 2

Statical and Dynamical Harmonic Components of the Deflection of the Shaft, Rectilinear Crack with 50\% Depth

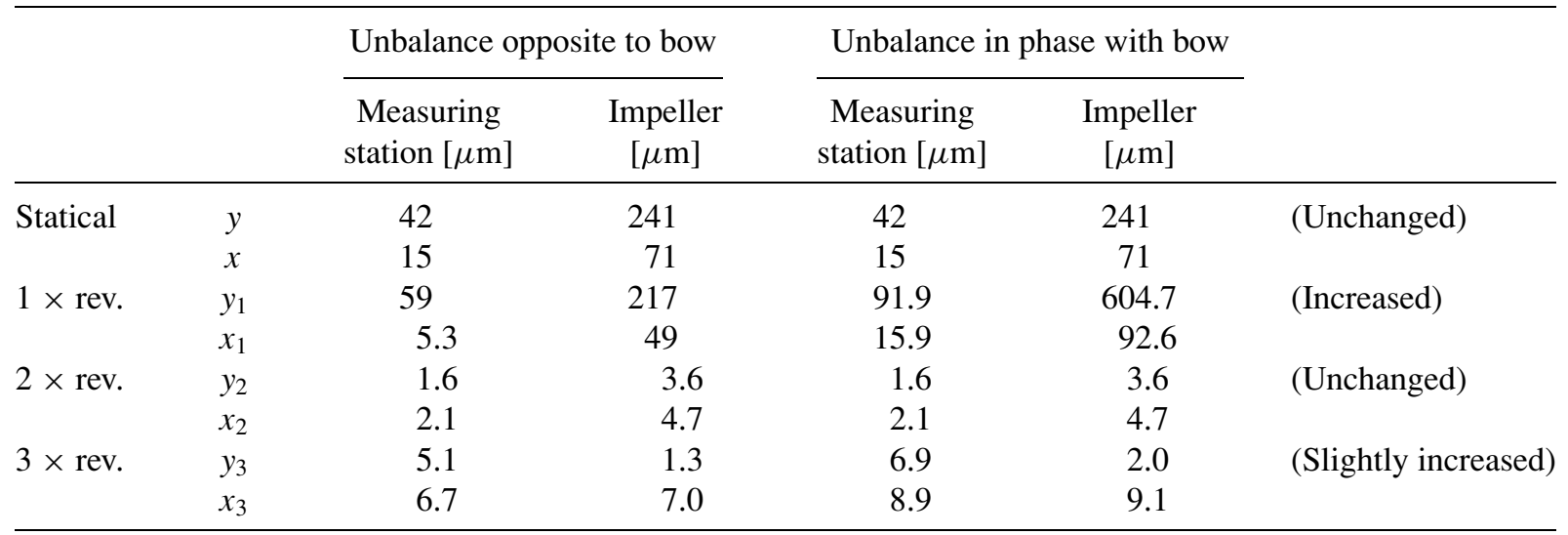

in the measuring station, which means that the vibration amplitudes are at least $20 \%$ of its maximum, located close to the excitation.

If the phase of the unbalance changes, both the statical deflection and the $2 \times$ rev. component remains unchanged. This last result is obvious for the static deflection, while for the $2 \times$ rev. component is due to the fact that with a perpetually open crack the $2 \times$ rev. component depends only on the depth of the crack and on the constant bending moment acting on the cracked section, which is due to the unchanged constant hydraulic load.

The $2 \times$ rev. component is very small; the arising of $1 \div 2 \mu \mathrm{m}$ could be masked by noise and is recognizable only with difficulties. Cracks with a lower depth would excite the $2 \times$ rev. components even less, therefore it could be difficult to detect their propagation from an abnormal evolution of the $2 \times$ rev. component (although this $2 \times$ rev. component is generally considered the most significant and accurate symptom related to a transverse crack in a shaft).

The small $2 \times$ rev. vibration amplitude is not due to a particular unfortunate measuring point, which can be seen from Figure 13, nor to a particular low q-factor at that speed, but simply to a small excitation, which means a small bending moment due to the constant hydraulic force.

If the crack had grown to a depth of $60 \%$, the $2 \times$ rev. component becomes more than double: $3.6 \mu \mathrm{m}$ and $4.8 \mu \mathrm{m}$, respectively, in $y_{2}$ and $x_{2}$ directions, which is still not very much.

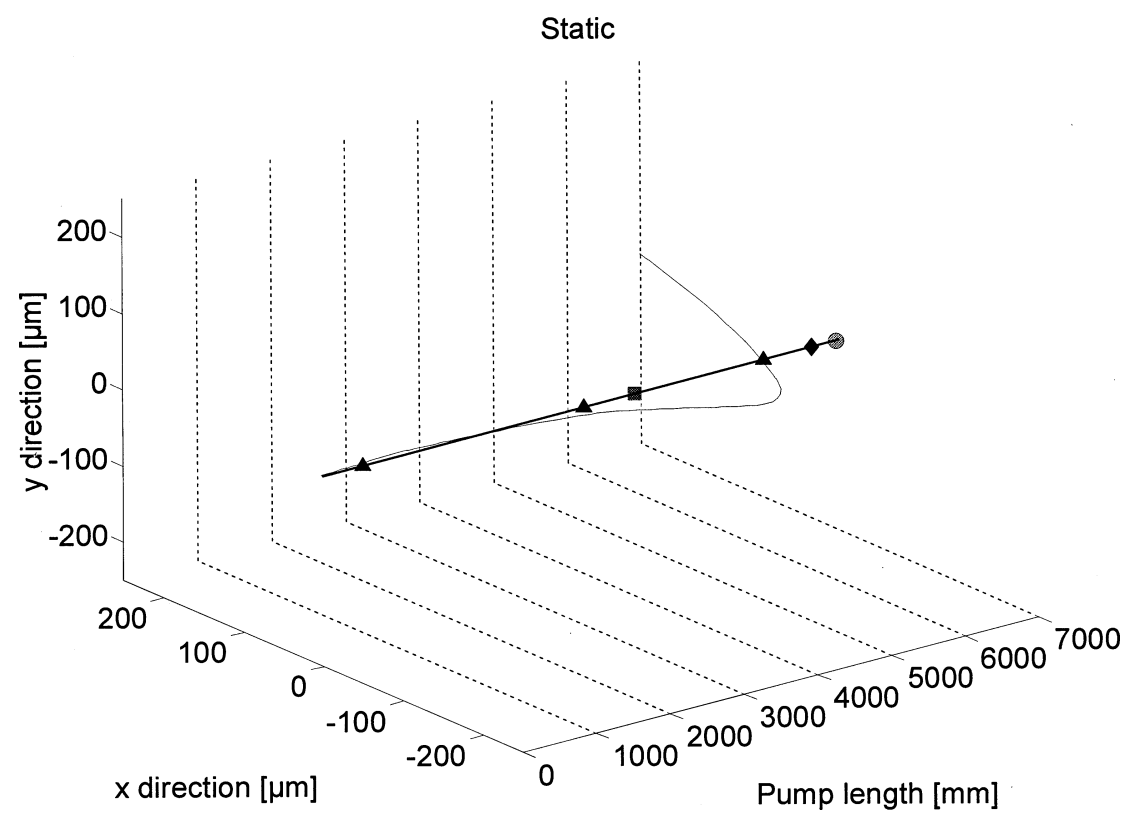

FIGURE 11

Statical deflection shapes ( $\boldsymbol{\Delta}$ bearing, $\downarrow$ seal, $\bullet$ impeller, $\boldsymbol{\square}$ measuring station). 


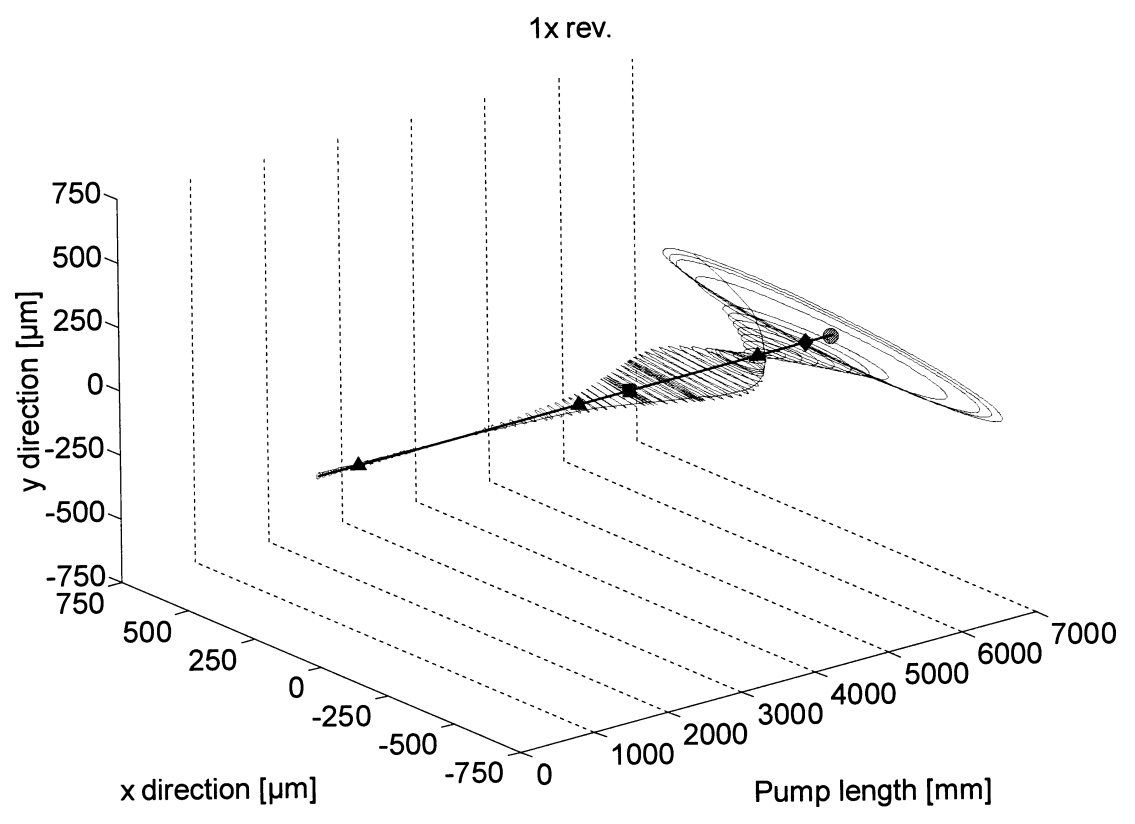

FIGURE 12

$1 \times$ rev. deflection shapes ( $\boldsymbol{\Lambda}$ bearing, $\downarrow$ seal, $\bullet$ impeller, $\boldsymbol{\square}$ measuring station).

In similar machines, it is reported that the $2 \times$ rev. component has reached $35 \div 50 \mu \mathrm{m}$. Such values can be obtained only by strongly increasing the hydraulic radial force; the $2 \times$ rev. components are in fact proportional to this force. The hydraulic force could be higher due to the deflections of the shaft, which force the impeller to an eccentric orbit. Furthermore, operation of the pump far from design point consistently increases the hydraulic load (Bently and Werner, 1990).
The $3 \times$ rev. component, which is generally smaller than $2 \times$ rev. component, is higher with respect to the $2 \times$ rev. component in this machine.

Since the crack excites rather big sized orbits in the seal (with amplitudes of $200 \div 300 \mu \mathrm{m}$, not shown in Table 2), the validity of the linear seal model could loose its validity. Higher stiffness does in generally correspond to a thinner fluid film, therefore the dynamic behavior has been evaluated by increasing the seal

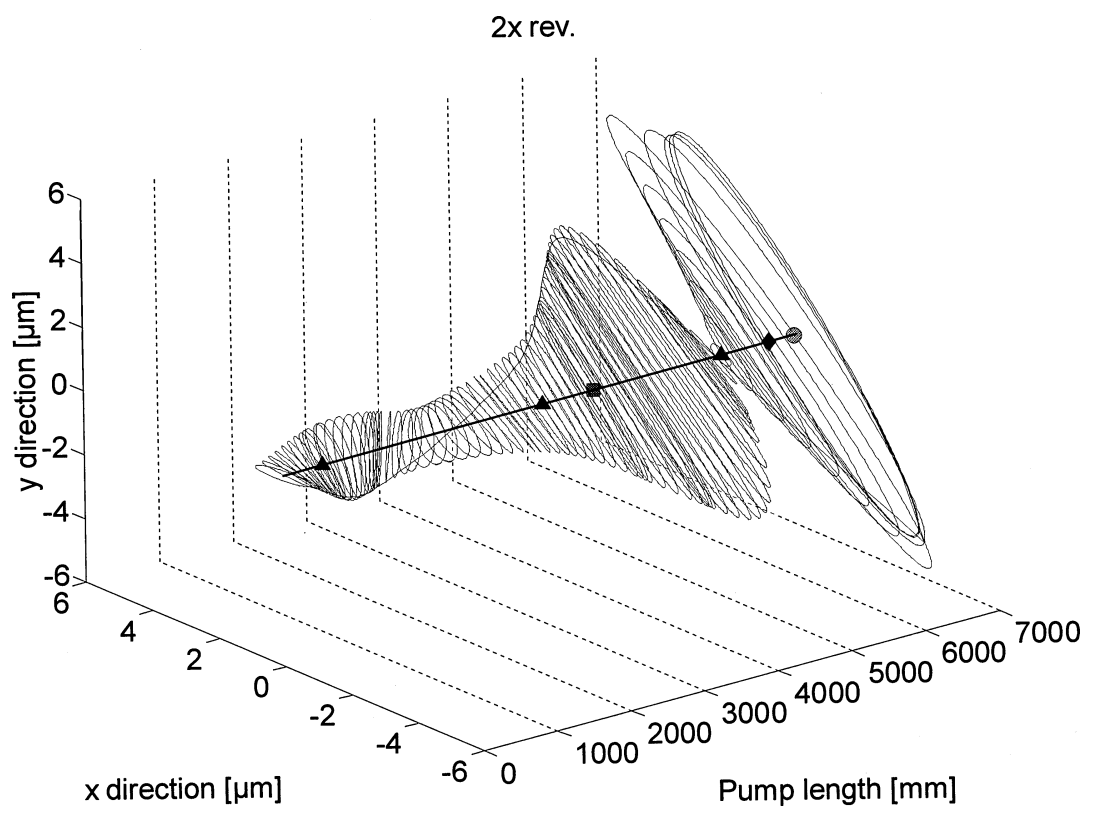

FIGURE 13

$2 \times$ rev. deflection shapes ( $\boldsymbol{\Delta}$ bearing, $\bullet$ seal, $\bullet$ impeller, $\square$ measuring station). 


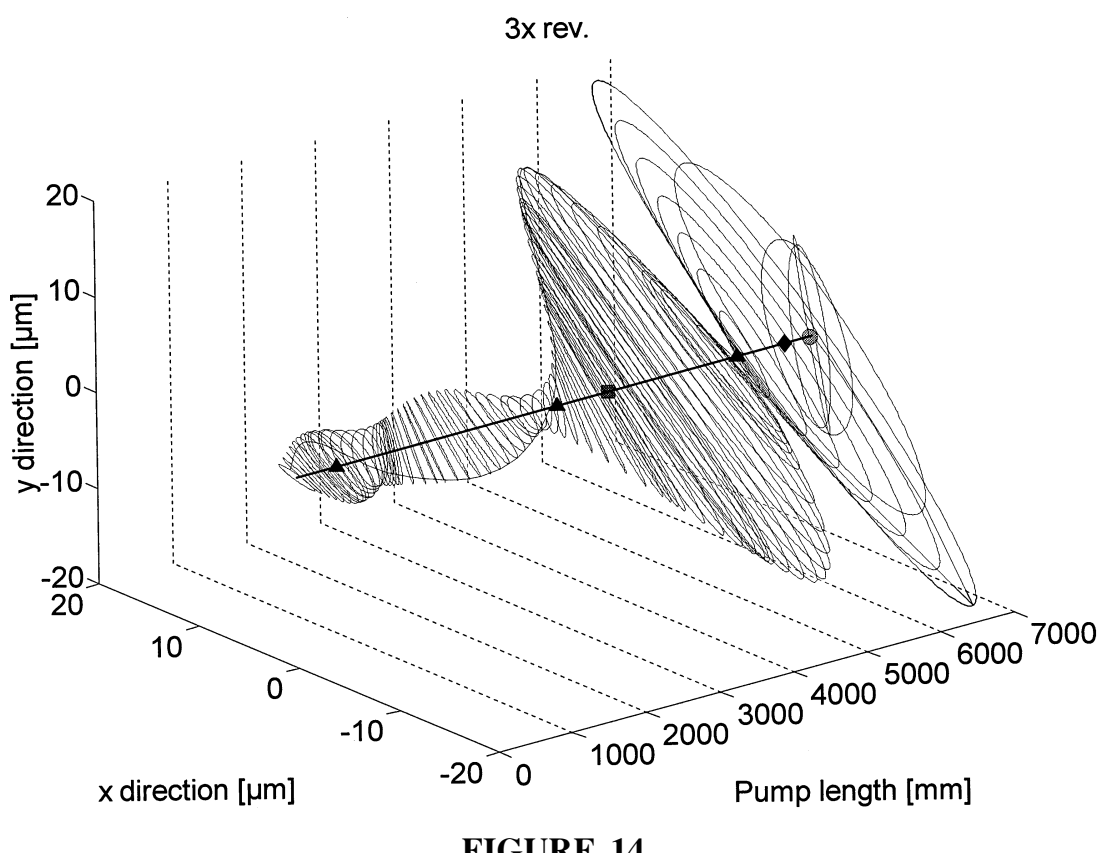

FIGURE 14

$3 \times$ rev. deflection shapes ( $\boldsymbol{\Lambda}$ bearing, $\bullet$ seal, $\bullet$ impeller, $\square$ measuring station).

stiffness coefficients by a factor of 10 . The critical speeds do change as well as the overall dynamic behavior at $1500 \mathrm{rpm}$. The results are the following:

- Statical and $1 \times$ rev. components in the measuring station are reduced, with respect to previous calculation.

- The $2 \times$ rev. components vanish in $y$ direction $\left(y_{2}=\right.$ $0.8 \mu \mathrm{m})$ and increase in $x$ direction $\left(x_{2}=6.7 \mu \mathrm{m}\right)$.

- The $3 \times$ rev. components increase consistently $\left(y_{3}=\right.$ $\left.8 \mu \mathrm{m} ; x_{3}=11 \mu \mathrm{m}\right)$.

In addition, these results seem to be inconsistent with measured values, but as previously stated, pumps of different manufacturers although similar in design can exhibit very different behaviors.

\section{CONCLUSIONS}

An original rotordynamics approach has been used to model the vibration behavior of a RCP shaft affected by an hypothetical transverse crack. The vibrational behavior has been predicted numerically for different operating conditions and at different stages of an assumed crack growth scenario. The calculations revealed the typical symptoms that could be found on the $1 \times$ rev. and $2 \times$ rev. components, with trends that were consistent with the experimental curves presented in the international literature on reactor cooling pump behavior. However, vibration levels, caused by cracks, with amplitudes similar to the measured values, can be obtained only by assuming much higher radial loads, which can occur when the machine is operating far from its design point.

\section{ACKNOWLEDGMENTS}

This work is partially funded by the MIUR (Italian Ministry for the University and Scientific Research) Cofinanziamento "TECNICHE DI IDENTIFICAZIONE DI MALFUNZIONAMENTI DI SISTEMI MECCANICI BASATE SULl'ANALISI DEL COMPORTAMENTO DINAMICO” for the year 2001.

\section{REFERENCES}

Bachschmid, N., Tanzi, E., Pennacchi, P., and Audebert, S. 2002. Transverse Crack Modeling and Validation in Rotor Systems including Thermal Effects, ISROMAC-9 Conference, February 10-14, Honolulu, Hawaii.

Bently, D., and Werner, M. 1990. Extending Machinery Life, Orbit, pp. 5-9.

Dimarogonas, A. D. 1996. Vibration of Cracked Structures: A State of the Art Review. Engineering Fracture Mechanics 55(5):831-857.

EPRI 1992. Proceedings: Main Coolant Pump Workshop-1991, Report TR-100299, pp. 1-608.

Grabowski, B. 1979. The vibrational behavior of a turbine rotor containing a transverse crack. ASME Design Engineering Technology Conf., St. Louis, Paper N ${ }^{\circ}$ 79-DET-67.

Kato, H., Kanno, H., Hosokawa, M., Watanabe, A., Shitara, C., Ashizawa, K., Miyano, H., Narabayashi, T., Iikura, T., Hayashi, M., Endoh, A., and Takehara, H. 1992. The Development of Advanced Nuclear Primary Loop Recirculation Pump (PLR pump) for BWR Plant Considering Thermal Fatigue Problem. Winter Annual Meeting of the American Society of Mechanical Engineers, November 8-13, 1992, Anaheim, CA, USA, pp. 157-162.

Mayes, I. W., and Davies, W. G. R. 1976. The Vibrational Behaviour of a Rotating Shaft System Containing a Transverse Crack, Vibrations in Rotating Machinery. Inst. of Mech. Eng., London, pp. 65-83.

Stepanoff, A. J. 1967. Centrifugal and Axial Flow Pumps-Theory, Design and Applications. Wiley Editor, New York. 

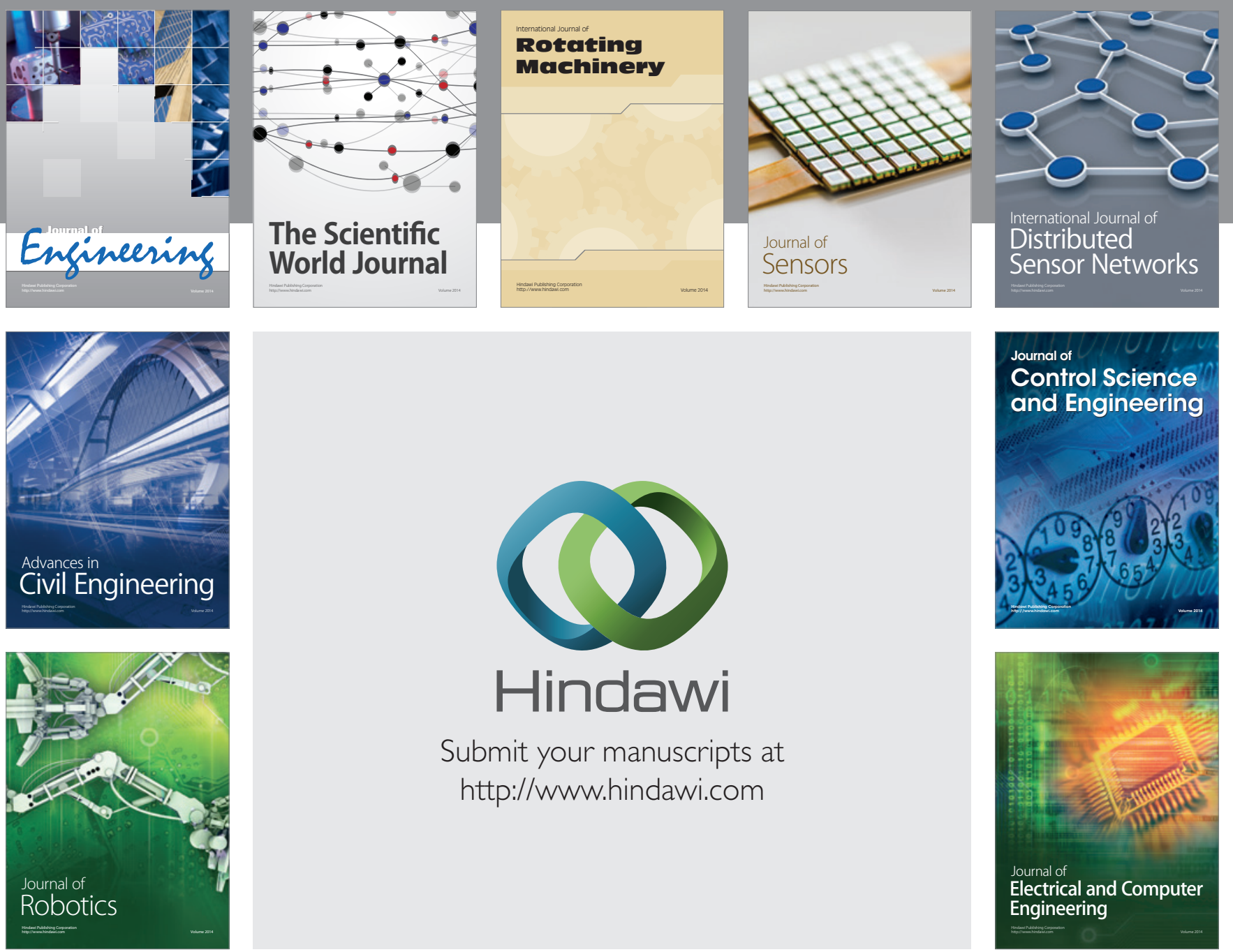

Submit your manuscripts at

http://www.hindawi.com
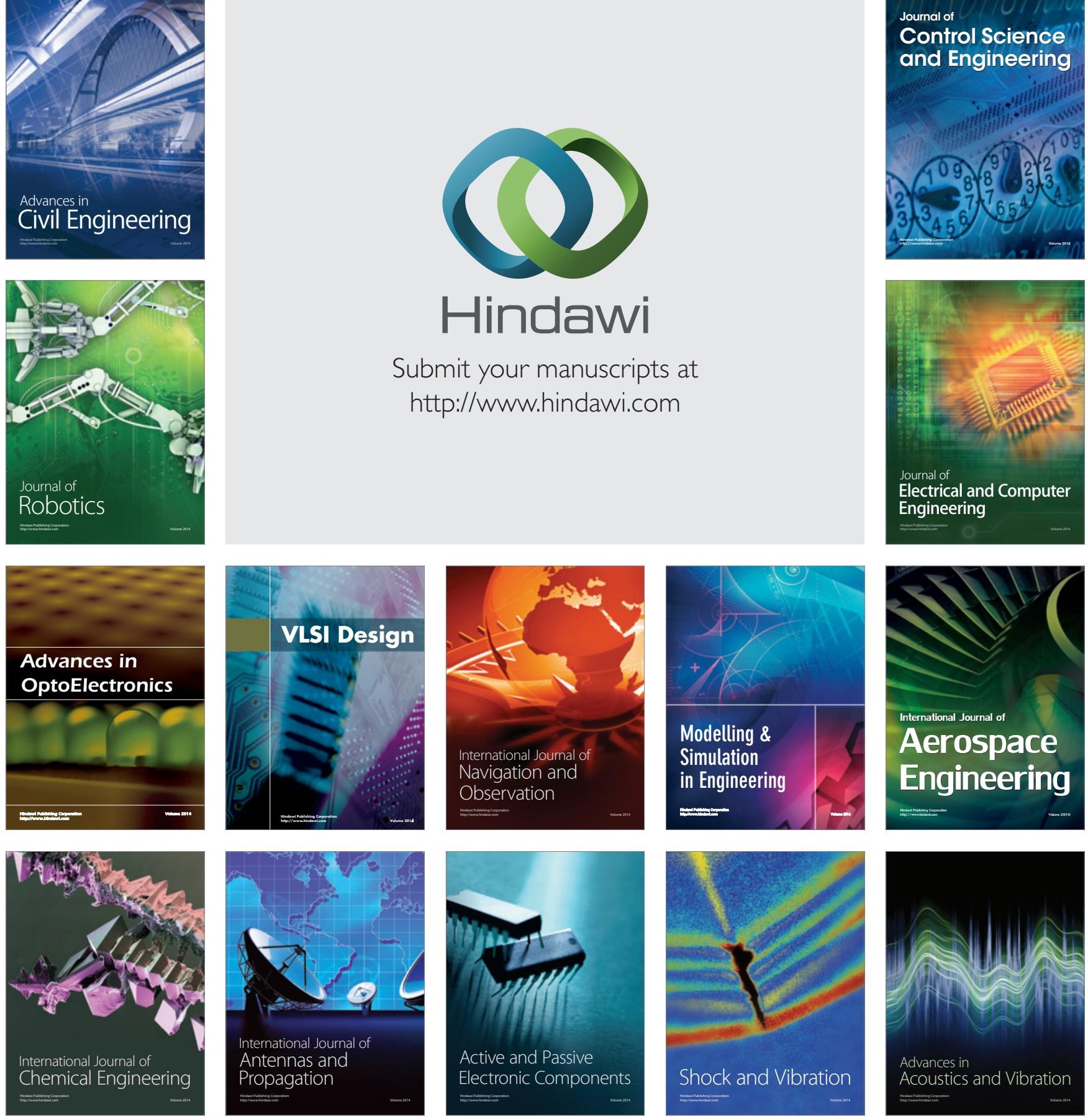